\title{
Review
}

\section{The socratic turn: Knowledge of good and evil in an age of science}

\author{
Dustin Sebell \\ University of Pennsylvania Press, Philadelphia, 2016, x+232pp., \\ ISBN: 978-0812247800
}

Contemporary Political Theory (2018) 17, S86-S89. https://doi.org/10.1057/s41296017-0117-z; published online 18 May 2017

Based solely on the merits of its analysis of the Phaedo, Dustin Sebell's book on the "Socratic turn" would be an outstanding work of scholarship. What makes this book even more remarkable is its suggestion that, by understanding the Phaedo, and in particular Socrates' critical response to his scientific predecessors, Plato teaches political theorists how to fend off the threat of reductive scientific naturalism (pp. 9-13). The Socratic Turn is thus doubly ambitious: not only does it strive to articulate the core of Socrates' rationalism, it also promises to show how said rationalism might protect political theory against the requirement that all knowledge conform to the standards of contemporary science. The complexity of Sebell's closely argued presentation makes it impossible to rehearse his case in full, but I will try to summarize how he intends to make good on his ambitions. I will also show how the book points beyond what it actually accomplishes.

Sebell begins by bringing to light the precarious position of contemporary political theory. While theorists have long struggled to justify their work against the critical judgment of the hard and soft sciences, Sebell shows how political theory is especially imperiled today by the rise of reductive naturalism. Reductive explanations - be they neurological, biological, or even sociological - tend to flatten or undermine the seriousness of human concerns by turning the agent into a passive effect of some form of causal determinism. Now more than ever, political theorists, especially if they want both to respect the authority of natural science and to be internally coherent, need to show why the objects of their theorizing concerns such as justice, love, friendship - are not better explained by the powers of non-human causes.

According to Sebell, Socratic philosophy affords political theory the means it needs to defend itself. By critically tackling the reductionism of his philosophic predecessors, Socrates shows that neither reductive materialism nor teleological reasoning satisfies the standard of intelligible necessity, which is the measure of genuine science. In response to this theoretical impasse, Socrates finds alternative,

(C) 2017 Macmillan Publishers Ltd. 1470-8914 Contemporary Political Theory Vol. 17, S2, S86-S89 
non-reductionist grounds in his dialectical approach to the beings, a mode of analysis which focuses principally on mind and form and their expression in human speech. More precisely, Socrates learns that a cogent engagement with the beings must cede the "primacy of form" (pp. 70-71, 76), which means that Socrates treats the objects of experience, because they "depend on mind for whatever unity they have," as if they had their own distinct integrity. This includes objects of moral or political experience as well (p. 13). Unlike his predecessors, who assume that the primacy of material nature (physis) entails the philosophic insignificance of convention (nomos), Socrates approaches moral phenomena on their own terms, which allows him to develop a genuinely scientific understanding of human values (p. 111).

On Sebell's account, Socrates' turn away from natural science and his subsequent intellectual development has four discernable stages:

Stage 1: Socrates the natural scientist, hopeful to be a convinced reductive materialist.

Stage 2: Socrates the student of Anaxagoras, disappointed in reductive causal explanation, but now hopeful about teleology.

Stage 3: Socrates the dialectician, disappointed in both reductive and teleological naturalism, but now hopeful about his Second Sailing - the dialectical analysis of beings as they are experienced and spoken about.

Stage 4: Socrates the successful dialectician, who somehow continues the search for causes, though he confines himself mainly to human phenomena.

Stages one through three, which represent a progress in Socrates' thinking about being and causality, are the focus of Sebell's book. He sets the fourth stage aside, claiming that an adequate treatment of it would require a separate and extended study of Plato's Apology of Socrates (p. 143). In so doing, Sebell concedes that he does not provide a full rendering of Socrates' Second Sailing, which is unfortunate, given the hopes he raises in his "Introduction." The exclusion means, therefore, that Sebell will not complete his account of how Socrates acquires genuine causal knowledge, though Sebell insists that Socrates contrives to do just this, albeit "indirectly" (p. 143).

Despite Sebell's understandable omission of stage four, his presentation of stages one through three, and especially his articulation of the impasse that leads to the turn itself, is very helpful. Again, the twists and turns of Sebell's reading prohibit direct recapitulation; suffice it to say that Socrates faces a troubling impasse when he comprehends, first, that the limitations of materialist reductionism culminate in the primacy of form; and, second, that the primacy of form cannot be given teleological support - despite the promise that form somehow betrays evidence of an ordering mind. As Sebell suggests, these two core realizations force Socrates to see the impossibility of "science in the fullest sense" (pp. 97, 102).

(c) 2017 Macmillan Publishers Ltd. 1470-8914 Contemporary Political Theory Vol. 17, S2, S86-S89 S87 
Thus, he cannot presume the existence of nature (physis), i.e., the existence of a mentally accessible, rationally ordered whole. This theoretical impasse occasions another equally vital realization: Socrates cannot assume that moral phenomena, including the belief in supervening gods, are mere artifacts of convention. In fact, at stage three, Socrates now believes that some version of the poet's cosmos, where moral concerns are given divine support, remains a "permanent possibility" due to the inadequacy of all science (p. 103). To the extent that science fails to achieve its object, this failure effectively recovers the moral-political-religious perspective from those critics who rely presumptuously on the authority of nature.

On Sebell's reading, therefore, Socrates' turn to the study of human experience, specifically human speeches, has two principal motivations. The first is his methodological response to the primacy of form. In contrast to his philosophic predecessors, Socrates claims that engaging solely with sense data results in "soulblindness." He turns, instead, to what humans say about the world, since it is in speech (logos) that mind's encounter with form is given articulation, thus affording access to the class character of being (pp. 107-108, 111). The goal of Socrates' dialectical method is to arrive at descriptive definitions of the beings, which start first as hypotheses about the nature of each being and are then tested rigorously for internal and external coherence. The prime objective here seems to be a kind of taxonomical set of non-contradictory definitions of the beings according to their form or class character (p. 111). Socrates weighs the appropriate empirical evidence, but the method is governed ultimately by logical coherence or the principle of non-contradiction (p. 129).

Now, it is crucial to realize that Sebell is not arguing that Socrates' method is wedded to the thesis of separate forms - despite all dialogic evidence to the contrary. On Sebell's view, the separate forms are meant, rather, as exoteric cover, a teaching for those like Simmias and Cebes, non-philosophers who have not fully come to grips with their hopes and fears, particularly their fear of death (pp. 135-143). Sebell believes that Socrates needs such a teaching because Socratic dialectics challenges the hopes cherished by most non-philosophers. In so doing, dialectics invariably arouses anger; but this anger can be defused if one is persuaded that some permanent and perfect instantiation of the source of hope (e.g., justice, beauty) exists in a kind of heavenly space. In other words, since the questioning of justice shakes the opinions we rely on to shield ourselves from the truth of our mortality, we are more tolerant of such questioning if we believe that Socrates thinks that true justice exists somewhere outside the imperfect realm of appearances. Sebell argues, however, that Socrates himself cannot be serious about the thesis of separate forms because the thesis is ultimately incoherent (p. 134).

The second motive driving Socrates' turn is his effort to learn his mortality and to purify his experience. This aspect of Socrates' method, though underdeveloped in the book, is vitally important to Sebell's overall argument. He both claims and insinuates that his Socrates, because of dialectical inquiry, has a kind of perfected 
soul (p. 105), and whatever else Sebell means by perfection, it clearly entails something like equanimity in the face of death, which, for Sebell, is an essential precondition for adequate theoretical reflection. The liberation from fear amounts to a liberation from hope; Socrates, reconciled to his mortality, is, thus, in the best possible place to allow his soul to genuinely reflect the order of the whole (p. 105); he can trace the articulated order he perceives, confident that he is not unwittingly forcing the beings into conceptual categories that might have once appealed to his hopes or sense of wonder.

Both for the student of Plato and the theorist concerned with the problem of naturalism, Sebell's account of the "Socratic turn" is valuable reading. Not only does Sebell provide a most helpful discussion of Socrates' critique of ancient science, he also offers a strong account of how Socratic philosophy is informed by that critique. The book does not allow us, however, to know if Socrates' rationalism truly fulfills all that Sebell promises on its behalf since, as noted, Sebell omits the fourth and perhaps most important stage of Socrates' development. The reader will look forward to a sequel, where, in addition to providing a fuller defense of his view, Sebell might consider developing his account of psychic perfection, providing examples of Socrates' definitions and explaining how such definitions rise to the level of knowledge or genuine science. This would, finally, provide a more direct engagement with modern science itself, since the current argument assumes, but does not establish, an equivalence between ancient and modern materialism.

Paul Diduch

University of Colorado Boulder, Boulder, CO 80309, USA paul.diduch@colorado.edu 